\title{
The Development of Social Media and its Impact on the Intercultural Exchange of the Olympic Movement, 2004-2012
}

\section{Yinya Liu}

To cite this article: Yinya Liu (2016) The Development of Social Media and its Impact on the Intercultural Exchange of the Olympic Movement, 2004-2012, The International Journal of the History of Sport, 33:12, 1395-1410, DOI: $10.1080 / 09523367.2017 .1285285$

To link to this article: https://doi.org/10.1080/09523367.2017.1285285

曲 Published online: 21 Feb 2017.

Submit your article to this journal ๘

Џ Article views: 504

Q View related articles $\widetilde{ }$

View Crossmark data $\asymp$

Citing articles: 1 View citing articles $₫$ 


\title{
The Development of Social Media and its Impact on the Intercultural Exchange of the Olympic Movement, 2004-2012
}

\author{
Yinya Liu (iD \\ Chinese Studies, Maynooth University, Maynooth, Ireland
}

\begin{abstract}
The development of social media, in the form of Internet and mobile platforms, has rapidly flourished in the early twenty-first century. The changes in broadcasting forms of the first three Olympic Games of the twenty-first century, Athens 2004, Beijing 2008 and London 2012, have corresponded and reflected the speedy expansion of this social media. This phenomenon invites not only attention to the historical transformation of the roles of media for the Olympic Games but also reflection on the concept of culture and intercultural exchange based on this phenomenon. This paper studies the relationships between social media, cultural exchange and the Olympic Games in the context of globalization. It argues that the characteristics of social media as 'participation; openness; conversation; communities; connectedness' will meet up with the goal of the Olympic Movement and aid the realization of the Olympic Ideal.
\end{abstract}

\section{KEYWORDS}

Olympic Games; Social Media; Socialympics; cultural exchange; globalization

\section{Introduction}

The importance and significance of media in the promulgation of the modern Olympic Games was recognized by Baron Pierre de Coubertin, the founder of the International Olympic Committee (IOC) at the end of the nineteenth century. Along with the development of media technology in the twentieth century, however, the use of social media in the twenty-first century has increased rapidly. In fact, the user numbers, user coverage and use frequency of social media, mainly in the forms of online and mobile telephone platforms, have changed exponentially over the span of the first three Olympic Games of the twentyfirst century: the 2004 Athens Games, the 2008 Beijing Games and the 2012 London Games. It is significant to examine the roles and changes of media in the organization and promotion of these three Games because this bears witness to the major turning point of the development of media itself as it moves away from traditional media forms of newspapers, magazines, radio and television, and towards new media forms of Internet-founded social media and mobile-telephone platforms.

The aim of the paper is to explore the relationships between social media, cultural exchange and the Olympic Games in the context of globalization. The most distinguishing feature 
of recent social media in the context of the Olympic Games is the interactivity of different cultures in a global context. This intercultural exchange of the social users associated with the Olympic Games (2004-2012) is the main concern of this paper. The paper is divided into four sections. The first section supplies a theoretical foundation for cultural exchange, and we also evaluate various voices on the concept of culture and intercultural exchange and its most updated development. Section two addresses the development of Olympic Media and its impact on the organization of the Olympic Games. In this section, we tentatively propose that a fifth period of 'Socialympics' has arrived and explore the inside of social media and the way in which these platforms link to the Olympics and form a 'Socialympics'. Section three is a case study that examines the changes in the broadcasting and media of the Olympic Games between 2004 and 2012 and analyzes the interrelation between the Games' organization and the relevant data. In the final section, we deal in particular with the relationship between media cultural exchange and the Olympic Games in the context of globalization.

\section{The Concept of Culture and its Development in the Context of Globalization}

Before we examine cultural exchange via social media in the context of the Olympic Games as a global event, it is of importance to define the concept of 'culture' because this term can refer to many things. Eliot proposes three important conditions for defining culture. ${ }^{1}$ The first is organic structure which emphasizes the growing characteristics of this concept. The second condition highlights the importance of local cultures. And, the last condition indicates the balance of unity and diversity in religion. Eliot reminds readers that the term culture is applied to 'the development of an individual, of a group or class, or of a whole society', but among these three categories, Eliot believes that the culture of the society is fundamental. ${ }^{2}$ Eliot's definition of culture is mainly from the perspective of literary criticism and was proposed in 1948. He has nonetheless articulated the dynamic, geographical and plural characteristics of this concept, which are still appropriately applied to its discussion today.

With regards to the concept of media culture, this term falls under the category of cultural studies and the major influence of mass media in the way meaning is organized in the twentieth century. Kellner argues that 'media culture is now the dominant form of culture which socialises us and provides materials for identity in terms of both social reproduction and change. ${ }^{3}$ In our context of discussion, the broadcasting of the Olympic Games is delivered by means of images, sounds and spectacles in the form of radio and television, and now online and mobile platforms via social media. Thus, we will limit our analyses on cultural exchange of the Olympic Games in the term of media culture. The reason is that social media is now the main platform for individuals to create their national and cultural identities, which has produced a new phenomenon of a 'global village' or globalization.

The concept of globalization is also growing and has its distinctive features when it is applied to the discussion of the Olympic Games. Considering Olympic Games as media events, Roche distinguishes two paradigms of globalization, 'basic globalisation' and 'complex globalisation'. These two paradigms demonstrate the development of the understanding of the concept of 'globalisation'. Globalization is not only a process of international integration but also a process to reveal the differentiation and particularization on the 'sub-national 
levels' and 'trans-national levels'. It is exactly this complex paradigm of globalization that inevitably invites various discussions on cultural phenomena.

Hence, we will briefly discuss the distinctions between multiculturalism, cross-culturalism and interculturalism with regard to the topic of cultural exchange in the postmodern cultural context. The discussion is limited in the range of media culture in order to distinguish its inner relationships, which are significant for further discussion. Based on this examination, we will pave the way for addressing the relationship between social media cultural exchange and Olympic Games in the context of globalization.

\section{Multiculturalism}

Multiculturalism is a broad concept that covers multiple cultural traditions in various aspects in different ethnic groups. This concept is mainly applied in political philosophy and used to respond to cultural and religious issues. Rosado articulates a definition of multiculturalism,

Multiculturalism is a system of beliefs and behaviours that recognises and respects the presence of all diverse groups in an organisation or society, acknowledges and values their socio-cultural differences, and encourages and enables their continued contribution within an inclusive cultural context which empowers all within the organisation or society. ${ }^{5}$

From this definition, we can see, all diverse groups will be respected by their cultural diversity in social arrangements within a particular nation or cultural group, but the cultural interactivity between them is not a necessity.

\section{Cross-culturalism}

Cross-culturalism, by contrast, mainly deals with cultural interactivity, especially in literary and cultural studies. Compared to multiculturalism, this concept emphasizes how the diverse groups reach across cultural boundaries between nations or social groups, and thus are open to change. In the postmodern period, cross-culturalism indicates that the boundaries of human relationship would play a role of separation to clarify human existence but also could reveal deeper connections by revelation from the different other. ${ }^{6}$

\section{Interculturalism}

Multiculturalism defines its research objects in a particular nation or cultural group while cross-culturalism designates its objects between nations and social groups. Interculturalism refers to the interaction between people who are from different social or cultural groups when they come together. Cantle argues that 'Inter-culturalism can potentially offer a more dynamic model, capable of coping with ever changing patterns of diversity and hybrid identities.?

From the brief review of these three concepts, it seems interculturalism would be the most appropriate concept for the discussion on the relationship between cultural exchanges via social media in the context of Olympic Games. However, there are controversial viewpoints on the distinction between 'multi-culturalism' and 'inter-culturalism', so we also need to clarify the controversies before we apply it to our discussion.

Cantle argues that interculturalism would replace multiculturalism as a framework because it provides a new model to support the cohesiveness of communities. ${ }^{8}$ By comparison, 
Meer and Modood give a 'no' to the question originally raised by Lentin about Cantle's argument - 'is inter-culturalism an 'updated version' of multiculturalism?'.9 They argued that interculturalism should be able to provide a clear perspective in political discourse, otherwise, it only plays a complementary role to multiculturalism and is impossible to replace the concept of multiculturalism. ${ }^{10}$ Levey, however, notes the distinction between 'hard' and 'soft' versions of interculturalism - hard mode emphasizes the fundamental difference between these two concepts, while soft mode accentuates the distinctive focuses between them. ${ }^{11}$ But this 'hard-soft' dual paradigm cannot thoroughly clarify their distinction because the main distinction between these two terms lies in the political consideration behind all scenarios and both terms are semantically problematic because they 'conjure images of culturalism ruling the roots. ${ }^{12}$ From Levey's point of view, it is more significant to clarify the concepts and to correct confusions. ${ }^{13}$ Thus, Bouchard has clarified the concept 'inter-culturalism' and provided some basic principles, paradigms and characteristics on it. ${ }^{14}$ Although the main topic is intensively argued on the management of ethnocultural diversity in Quebec, this article significantly provides at great length seven characteristics of interculturalism. ${ }^{15}$ These seven characteristics are: (1) majority/minorities duality; (2) a process of interaction; (3) the principles of harmonization: a civic responsibility; (4) integration and identity; (5) elements of $A d H o c$ precedence for the majority culture; (6) a common culture; (7) the search for equilibriums. In addition, Bouchard also argues that interculturalism has essential roots in Europe 'as a formula for coexistence in the context of diversity. ${ }^{16}$ But we will maintain and extend it to the global context of Olympic Games in our discussion. In other words, interculturalism is also a formula for examining the coexistence of cultural diversity and exchange via social media for the Olympic Movement in the twenty-first century.

By means of proposing characteristics of interculturalism, Bouchard indeed provides a clearer platform for us to analyse our topic. Thus, we will concentrate on these characteristics and apply them to our study on the role of social media and the development of media culture in the Olympic context. These characteristics are particularly related to an overwhelming impact of social media on the Olympic Games. This phenomenon is named as 'socialympic'. In the next section, we will discuss the development of Olympic media and indicate how the developments affect the organization of Olympic Games.

\section{Development of Olympic Media and its Impact on the Organization of Olympic Games}

The relation between the roles of media and the organization of Olympic Games or the Olympic Movement has been discussed by several scholars since the late twentieth century. ${ }^{17}$ Their focuses vary, from historical and commercial perspectives, ${ }^{18}$ to cultural, international, supranational and global perspectives. ${ }^{19}$ The Olympic Games are one of the most influential mega-events in the world, and so, they have a close relationship with various forms of media, especially in the time frame that we have set for this paper, from 2004 to 2012. During this time frame, media is not only the carrier that delivers the entire process of the Games but also an essential part of 'event-based popular cultural forms' and 'social movements. ${ }^{20}$ Thus, the development of Olympic media reflects the functions of media both at and in different time periods and indicates also its pattern and impact on the Olympic Games themselves in their history. The main function of Olympic media in the early twenty-first century, 
nonetheless, still partially follows the traditional functions of press, namely: 'to inform (the news function), to persuade (the advertising function), to entertain (the features function), and to pass on the cultural heritage (the educational function).21 ${ }^{21}$ Therefore, we will start from the review on the impacts of these functions in traditional media.

Owing to his awareness on the importance of mass media, Baron Pierre de Coubertin devoted a considerable amount of his efforts in public relations expertise with respect to promoting the Olympic Games in the form of newspapers and magazines. ${ }^{22}$ This is the first period of the development. From the beginning of the modern Olympic Games, for instance, 'sports writers' for 'sports pages' had been set up in order to satisfy the enthusiastic needs of the 'athletic craze' in the United States. ${ }^{23}$ In comparison to newspapers and magazines, which would retell the Olympic performances in a heroic, historic and even mythic way, radio in its way had the capacity to deliver the major sports events "to the world" as a "live" event at which an international audience would feel as if they were "present" as witnesses, ${ }^{24}$ especially in the 1932 Los Angeles Olympics and the 1936 Berlin Olympics. At this time, the press was the main format of mass media and still dominated the sources of Olympic news until television entered the everyday life of the audience: the 'event-witness function' has overwhelmed the 'noticeboard/record-keeping function. ${ }^{25}$

During the second period of 'television before satellites' (1936-1964), ${ }^{26}$ television started to transform the nature of the organization of Olympic Games on 1 August 1936, in Berlin. It was the opening of the 'TV age of sports. ${ }^{27}$ This can be discussed, but is not limited to two aspects. The first is that, in this period, the Olympic Games develop into a 'media event' as television becomes increasingly popular. According to Roche, 'A criterion for qualifying as a media event is that people in many nations feel obliged to watch and feel privileged to be able to witness the event. ${ }^{28}$ This accessibility and popularity of television, therefore, provides the possibility for the participants to 'be there', though in the form of compensation by means of moving pictures, information and commentary, and so forth. With regard to the 'media event' features, Dayan and Katz remark that there are three partners for television events: the organizers, the broadcasters and the audiences. The main function of the organizers is to properly allocate all required elements for the Games; the main function of the broadcasters is to reproduce and deliver information about the Games to the audiences; the main function of the audiences is to receive the information from the broadcasting and to witness the event. All these partners are indispensable for completing a media event for television. ${ }^{29}$ Roche adds that the state and market should also be taken into account when considering the 'informal social contract' of the 'negotiated partners' in a media event. ${ }^{30}$ The analyses of these elements emphasize the significant roles of media in the context of Olympic Games. Without the development of media, especially in the form of television in this period, the scale and the influence of the Olympic Games would not be so crucially turned into such global public events that can 'make history', ${ }^{31}$ but they would just be sporting events in the history of their time. The second aspect of the 'TV age of sports' indicates the commercial relationship between media and the Olympic Games. Slater observes that the Melbourne 1956 Games is a 'key turning point' in this relationship because, at this stage, the realization is that the 'Olympics could be a source of profit. ${ }^{32}$ When we analyze the Olympic Games as a 'sports-media complex' ${ }^{33}$ or a 'complex cultural form, ${ }^{34}$ the commercial feature of Olympic television as a hidden Olympic movement element must be acknowledged. The organizations of the Games, after all, need revenue and the sale of television rights for the 
Olympic Games provides financial profit. Therefore, it is obviously exceedingly difficult to keep the balance of the leading forces between media, the market, the state and the Games.

This situation lasts and even deepens till the third period of 'Satellite Television before the Internet' (1968-1988). ${ }^{35}$ The main change here is that satellite enables real-time broadcasting of the Olympic Games, which leads to a continuous increase in broadcasting rights fees. ${ }^{36}$ Meanwhile, various corporate sponsorships form the major source of income of the organization of the Olympic Games, though it also decreases the dependence on television rights. Thus, it is not surprising to note that the situation of providing and maintaining an unbalanced relationship between the needs and pressure of financial support and the autonomous rights of the Olympic Committee has been a major struggle. Who, or, perhaps more accurately, what, then, is playing the leading role in the organization of the Olympic Games? At this stage, this question is no longer hidden but decisive regarding the further development of the Games.

In order to answer this question, the IOC explained a new strategy, which indicates that the development enters a fourth period, 'the era of Olympic dominance' (from around 1992 into the future):

Included in the broadcasting agreements are the rights to broadcast Games for which host cities have not yet been chosen, a clear indication that choice of city is in no way influenced by the commercial considerations of broadcasters ... Previously there used to be extended debate over broadcasting time-zones and the value of the local market to sponsors. All of this is now of minimal importance as broadcasters and sponsors focus on the global nature of the Games. ${ }^{37}$

The determination of the IOC, therefore, demonstrates, on the one hand, the global influence of the Olympic Games in the Olympic television period and, on the other hand, shows a concern to maintain the significant global nature of the Olympics over the impact of media. This has been further specified in the annual Olympic Broadcasting Reports. ${ }^{38}$

From the foregoing discussion, the four distinct time periods have been reviewed in relation to the role of 'media event' and the role of 'commerce' in the process of the organization of the Olympic Games. The development of media, however, did not stop but reached another stage, which came into prominence for the organizers and spectators of the Olympic Games in the early twenty-first century. This phenomenon emerged from the 2008 Beijing Olympic Games and evolved into a mature form in the 2012 London Olympic Games. In the consideration of the development of a media event and its impact on the Olympic Games, I agree with Larson and Park's view that a long-term view of a media event should be taken rather than a short-term view, though their concerns were mainly on the 'Socio-Political Process. ${ }^{39}$ Therefore, in the next section, we will take the broadcasting of the Olympic Games (2004-2012) as a case study in order to outline and assess the interaction between the new form of media, social media with Internet and mobile platforms, and the Olympic Games. The following questions will be explored and answered: (1) What are the differences between these three Olympic Games in regard to broadcasting; (2) What is the new form of the media and its new features as distinct from the media forms in the previous four periods?; (3) What is the impact of this new media on the reception and our understanding of the Olympic Games? 


\section{A Case Study: The Opening Ceremonies and Broadcasting of Olympic Games (2004-2012)}

It is both of importance and of significance to take together and analyze the broadcasting of the three Olympic Games hosted by Athens, Beijing and London from 2004 to 2012 because this time span reflects the major shifts and factors in the historical, social, cultural and economic elements that contribute to the organization of the Games and, in particular, the crucial information of the 'opening ceremonies' and the formative factors of the broadcasting. In this section, therefore, we will begin by briefly reviewing the content of the opening ceremonies of these three Games, and then compare the data of the performance of the audiences provided by Olympic Broadcast Reports, for the purpose of noting the changes in approaches and changes of audience receptions in relation to these three Games. We will further demonstrate the new form of media and its features which has emerged from the Beijing and London Olympic Games.

\section{Athens 2004}

The opening ceremony of Athens 2004 was held on 13 August 2004 and the motto of the Games was 'Welcome Home'. Athens Olympic Broadcasting, as the host broadcaster, provided high definition for the first time in Olympic Games broadcasting history. ${ }^{40}$ The opening ceremony was directed by Greek dancer and choreographer Dimitris Papaioannou. The ceremony unfolded the nationalist sentiments on the reflections between the ancient Greece' and 'new Greece." ${ }^{41}$ The 'ancient Greece' recorded the first modern Olympic Games in history in 1896 and the 'new Greece' witnessed the postmodern Olympic Games after more than 100 years. By presenting the symbols that were used in the ceremony, both the historical significance of the Olympic spirit and the recurrence of the ancient Greek civilization recalled the audience reception on the foundation of Western civilization.

\section{Beijing 2008}

The opening ceremony of the Olympic Games in Beijing was held on 8 August 2008 and the motto of the Games was 'One World, One Dream. This was the first time in its history that China hosted the Olympic Games and the director was Chinese filmmaker Zhang Yimou. The main theme of the opening ceremony was harmony and this theme penetrated the event by use of different patterns of manifestations, e.g. scroll painting, written characters, opera. As articulated in a report, the central ideas of this opening ceremony were peace, unity and friendship, which indicate the concept of harmony. ${ }^{42}$ The use of symbolism is a common feature of many opening ceremonies and Zhang is famous for using symbolic images and performances to illustrate cultural elements with Chinese characteristics. Under the main theme 'harmony', a similar sub-theme is comparable to Athens 2004's opening ceremony, which is the harmonious coexistence of historical traditions and modern development. ${ }^{43}$

\section{London 2012}

The opening ceremony of the London 2012 Olympic Games was held on 27 July 2012 and the motto of these Games was 'Inspire a Generation'. This was the fourth time in its history 


\section{Comparison between numbers of users from various media for Olympic Games (2004-2012)}

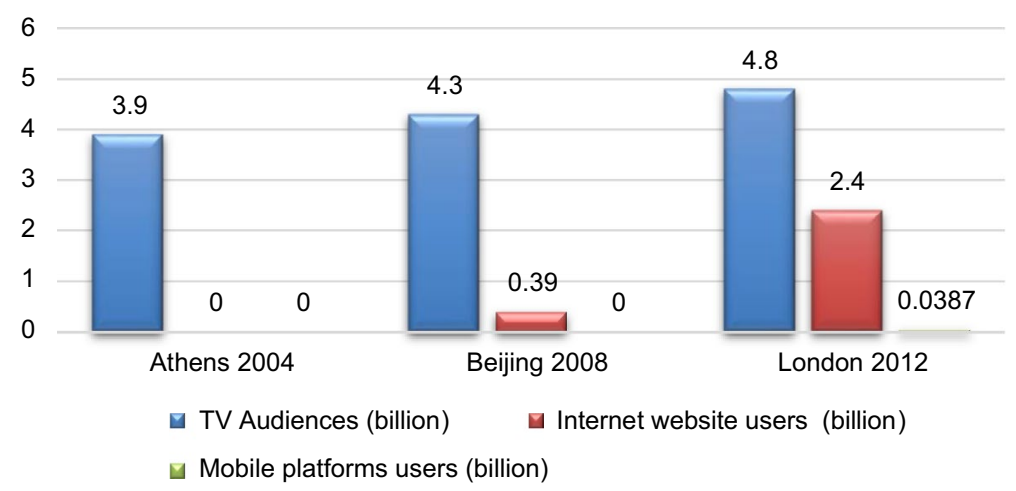

Chart 1. Source: Chart 1 is tabulated according to the 'Athens 2004 Olympic Broadcast Report','(Beijing 2008) Global Television and Online Media Report' and '(London 2012) Global Broadcast Report'.63

that the United Kingdom hosted the Games in London. It was directed by Danny Boyle, who is famous for winning an Academy Award. The opening ceremony also prolifically collected representative symbols and cinematic images to show the British history of struggles, political change, literary tradition, cultural movements and the British sense of humour. Children and young people featured in the ceremony reflected the motto for inspiring a generation, which also shared the theme of 'the past versus the future' with the previous two opening ceremonies.

\section{Analysis}

By analyzing the opening ceremonies as significant 'mega-events' and 'media-events', the motivation of the directors, which represented the organizers and producers, as well as reviewing the main content of the ceremonies regarding the embedded cultural elements, we will move to the third partner of a television event, the data analyses of broadcasting for the whole process of these three Olympic Games.

By comparing data from these three reports provided by Olympic Game organizers, especially in relation to the changes of 'Media forms' and 'Data of Internet and mobile platform', we can see the dramatic evolution of the media form towards the newly emerging social media via the Internet and mobile platforms. Though the television coverage and the number of the audiences, as traditional mass media have kept expanding stably, online and mobile platforms have shown a momentum of rapid development. This raises important questions: For instance, can we still define these online and mobile platform users as 'audiences' in a traditional way? Can we say that broadcasting must now be understood in a broader sense because the idea regarding whether or how to view the Games will be decided by individuals at hand, and not exclusively in the hands of broadcasting networks? The interaction on the Olympic topics has obviously been extended from one-sided communication to reciprocal communication. This raises the question: What kind of social, cultural and economic impact on the organization of the Games will occur with the change from the traditional television to online and mobile platforms? 
With regard to the analyses on the traditional mass media, firstly we will look at MacAloon's later work. He analyzes four genres of the contemporary Olympic Games: 'festival', 'ritual', 'spectacle' and 'game', ${ }^{44}$ which are intensively presented in the opening ceremony, and certainly, in the competitions. The analyses will mainly target the opening ceremony because this worldwide-witness event has already displayed the first three genres of the Olympic Games, as a prologue of the Olympic Games. And in the context of the 'TV age of sports' or 'Olympic TV', the spectacle genre from these four has taken over the priority of the other genres, ${ }^{45}$ especially the development of technology has provided a high-tech platform to realize the request of both the organizers and the audiences.

The content of the opening ceremony specifically reflects the inner connections between the organizers or producers and the audiences. Since commercial elements, however, have become inextricably related to the organization of the Olympic Games, the entire process of the Games necessarily becomes part of the Olympic industry. And opening ceremonies, as the most important symbols of this industry, are cultural and political festivals to demonstrate the Olympic meanings and values from both national and international perspectives. The organizers convey the echo of national history, popular culture, symbols and identities of the tradition, and, in a word, all the aspects that represent the essence of the host countries along with their understanding and expression of peaceful internationalism by means of mixtures of images and messages. The audience reception of watching both the opening ceremony and games can be discussed, at least, in two aspects. The first is the local audience who would receive the sense of national and historical identity, national pride and cultural citizenship, etc. The second is the audience from all over the world, who would receive new national and new 'post-national' conceptions from the ceremony in the context of globalization.

During the time period of 2004-2012, these three Olympic Games were held in a postmodern period, but they still maintained the mythic and ritual elements in the opening ceremony, while at the same time, strengthened the 'consumer culture', notably, with the development of mobile devices, which has maximized the autonomous roles of the ordinary audience and sports fans in the Olympic Movement. In other words, from these three Games, we have seen major, real and significant changes in the interaction between the organizers and audiences (individually, nationally and internationally) both from the opening ceremonies as well as in the competitions. It is, nonetheless, difficult to obtain a clear evaluation of the exact impact of this change precisely because it is developing so rapidly. We can say, however, that the fifth period of the relationship between the media and the Olympic Games has arrived - the period of 'Socialympic'.

It has been pointed out that the 2012 London Olympic Game was the most connected Olympics because of the overwhelming use of social media which, in turn, brought in 'Socialympics'. Various forms of social media contributed to this new wave, for example, Twitter, YouTube, Facebook, live blogs and so forth. As indicated in Chart 1, social media unofficially connected to the Beijing Olympics in an experimental way, but four years later the advancement of social media broke into the field of everyone's vision.

This can be proved by a statistic which demonstrates more detailed information about this change. Facebook only had less than one million members at the 2004 Olympics in Athens. The number of members increased to 90 million at the 2008 Beijing Olympics and by the time of the London 2012 Olympics Facebook had nearly 1 billion members. ${ }^{46}$ According to the most updated statistics from Facebook.com, '[there are] 1.09 billion daily 
active users on average for March 2016; 989 million mobile daily active users on average for March 2016; 1.65 billion monthly active users as of March 31, 2016; 1.51 billion mobile monthly active users as of March 31, 2016; Approximately $84.2 \%$ of our daily active users are outside the US and Canada. ${ }^{47}$ The situation of Twitter is similar. Twitter started in 2006 and there were around 3 million active users during the Beijing Games. ${ }^{48}$ Today, there are 310 million monthly active users and 1 billion unique visits monthly to sites with embedded Tweets. $83 \%$ of active users are on mobile facilities and $79 \%$ of accounts are outside the US. Twitter also supports more than 40 languages. ${ }^{49}$

The statistics of Facebook and Twitter, as examples, show the trend of future expansion of social media on the Olympic Games. The legislation issues of Socialympics have also been noted. ${ }^{50}$ Accordingly, we can summarize some characteristics of Socialympics: (1) it is an online Olympic Hub to connect fans with athletes via social media accounts. Traditional media is no longer the only source to access the news as well as the comments of the players and winners of the Games. (2) Sponsors on social media are more flexible and extensive. This will bring in more career opportunities to individuals who work online for the Games. (3) The social media connects the digital world to the physical world, ${ }^{51}$ for example, offline activities organized by online groups. There are also negative voices on the role of social media, which mainly concern athletes' personal privacy. ${ }^{52}$

In sum, social media provides opportunities for individuals not only to witness the Olympic Games, by viewing the opening and closing ceremonies or competitions but also for them to contact athletes both from their own nations and from other countries. The organizers can offer more feature materials and instant news online; audiences can express their comments and exchange information. In this sense, social media realizes the idea of 'desiring to see the local (self) as part of the global (Olympics)'. ${ }^{53}$ Social media users, therefore, have achieved the situation of 'being-there' with the athletes globally, technically speaking.

Thus, we can answer the questions raised earlier in this section. Regarding the first question, it is no longer appropriate to define the online and mobile platform users as traditional 'audiences'. According to the characteristics of Socialympic, the users would not just listen to or watch particular television or radio programmes. They would also leave comments at various platforms. The users' comments would be published widely and instantly through these platforms, which would not only be received by other users, but also by athletes who attend the Games and the organizers of the Games. Given this background, the relation between users, the relation between users and athletes and the relation between users and organizers implicate the features of interculturalism. All these relations carry duality and interaction in the global sense. Although the host city or country would highlight its majority culture, the global nature of the Games and the international nature of the social media provide a platform or space for other cultures to speak and communicate with ongoing communication on the same topic (the Olympic Games), which also have been deepening cultural exchange.

For the second question, Socialympic, as an emerging and developing phenomenon, decides that the spreading of information is no longer unidirectional but bidirectional or multidirectional. Socialympic is not only about information sharing but more about creating communities or networks for processing interaction on specific topics. These features of Socialympic indicate that, nowadays, broadcasting has to be understood in a broader sense because social media includes the technologies of delivering information as well as the 
functions of generating new approaches of sharing. For example, hashtag or metadata tag is a type of label used on social networks for efficiently spreading and sharing hot topics on particular events. Individuals could use hashtag to process 'deep mining' for searching most relevant information about the topic, e.g. the Olympic Games. In this way, social networks are multilayers; the structures of information are diverse and media culture are inclusive to users from different backgrounds.

With reference to the last question, at the current stage, there is no confirmed answer on the social, cultural and economic impact brought forth by the Socialympic because Socialympic itself is still a developing phenomenon. However, we can anticipate that issues of interculturalism will be embedded in all these impacts. Our review on the complex paradigm of globalization in section two indicates that globalization has developed into another stage where standardization or integration has been withdrawn while differentiation and particularization have been accentuated. Social media platforms are exactly the places for the audiences to express their comments in the 'sub-national levels' and 'trans-national levels' on Olympic related issues. This is a paradoxical situation: social media is a powerful approach to accelerate the process of international integration, while it also provides platforms for users to express their individual voices. This mechanism interestingly matches with the organization of the Games. As Roche argued, the Olympic Games is a global event as well as a media event. In this global event, the achievement of the Olympic Moto 'Swifter, Higher, Stronger' can only be realized by athletes' continuous breakthroughs. Successful organization of this event brings active participation of people from all over the world, in the past, by means of traditional media and today, social media connects organizers, audiences and athletes.

In this regard, as channels of communication, the social media platforms bring Game organizers, audiences and athletes from around the world together producing a highly globalized phenomenon which impacts socially, politically and economically on various aspects of our daily life. Yet, it is cultural exchange in particular that is arguably the first and foremost element which is embedded in these impacts. Thus in the next section, we will discuss cultural exchange via social media in the context of globalization.

\section{Media Cultural Exchange and Olympic Games in Globalization}

After we reviewed the development of Olympic media and its impact on the organization of the Olympic Games and work on the case study of the changes of the broadcasting of the 2004-2012 Olympic Games, we tentatively proposed that the fifth period of 'Socialympics' has arrived. In order to examine the theoretical foundation for cultural exchange under a new form of cultural exchange via social media, we also evaluated various voices on the concept of culture and its most updated development. In this section, therefore, we will intensively deliberate on media cultural exchange and Olympic Games in the context of globalization.

When MacAloon commented on 'the spectacle dimension of Olympics in the television age, he intimated that there would be both negative and positive implications for the ritual dimension of the Games but that there would consistently be a negative impact for the festive character of the Games. ${ }^{54}$ The reason he gives is that the Olympics on television would bring in 'inequalities and hierarchies of sport 'stars. ${ }^{55}$ According to Roche, 'Olympic TV addresses itself to presenting just such a unitary event, prioritising some (dominant, 
official) perspectives and narratives over others. ${ }^{56}$ Yet the emerging worldwide use of social media has changed the forms of exchange, most of which are embedded in the background of cultural exchange with the characteristics of interculturalism. For people who can afford the relevant electronics, social media has been a platform for life, or even a way of their daily life. Cultural exchange via social media has been boosted in every corner of our life to search for the right of individuals' voices, which includes the Olympic Games - an event that invites the host country to manifest its tradition, history and current development; an event that invites athletes from all over the world to compete in a fair play environment; an event that invites audiences from every country to witness achievements of human physical ability via athletic performances and exchange their excitements and opinions with the most convenient approach through social media.

Therefore, the mechanism of social media instinctively shuns 'inequalities and hierarchies', of sport 'stars' (social users can follow their favourite athletes' social media account to express their support) or of sport 'types' (social media would avoid the issue of the coverage rate of the unitary broadcasting system, for example, traditional broadcasting usually gives more coverage of the more popular sports type according to audience rating and sponsors' interest). We argue that this change is significant for both the users of social media and the organizers of the Olympic Games. The geographical and climatic factors of the participating countries determine the fact that athletes from each country would have different types of sports that they are competent in. The different populations of the participating countries will also influence the broadcasting rate of various sports competitions. Olympic TV presents the Olympic Games as a unitary event with a unitary approach but social media offers multilayered platforms for users to be aware of all these deeper factors existing in every aspect of the Olympic Games, when they search their favourite athletes or sports from these platforms, when they share their comments on the platforms and when they communicate with the users from completely different backgrounds. In this sense, an Olympic event is not only a media event, but also a cultural event. It is an event that links people together, deepening their understanding of sport and the Olympic Idea.

Therefore, we argue that by means of social media, the Olympic Idea can be delivered in the most efficient and original way. This ideal is stated in the first fundamental principle of Olympism,

Olympism is a philosophy of life, exalting and combining in a balanced whole the qualities of body, will and mind. Blending sport with culture and education, Olympism seeks to create a way of life based on the joy found in effort, the educational value of good example and respect for universal fundamental ethical principles. ${ }^{57}$

The goal of the Olympic Movement also reflects this ideal,

The goal of the Olympic Movement is to contribute to building a peaceful and better world by educating youth through sport practiced without discrimination of any kind and in the Olympic spirit, which requires mutual understanding with a spirit of friendship, solidarity and fair play. ${ }^{58}$

The characteristics of the social media can be seen as containing five aspects: (1) participation; (2) openness; (3) conversation; (4) communities; (5) connectedness. ${ }^{59}$ And interactivity, which is a defining feature of social media, connects these five characteristics as an essential factor. ${ }^{60}$ Thus, these characteristics of social media meet the requirements of the goal of the Olympic Movement and the ideal, which the Olympics seeks. 


\section{Conclusion}

The main concern of this paper is the intercultural exchange of social media users on the Olympic Games. From the foregoing discussion, the social media users, not in the traditional sense of audiences, can connect directly with their favourite sports stars, participate in online events, join online communities and have instant conversations with athletes or other users. These are entirely based on the premise that social media costs very little, is easy to manage and is quicker for updates and communication. If the Olympic Games provides the opportunity for a regular venue to set up 'a global village' every four years, social media now has become a tool of cultural transformation within this village. ${ }^{61}$ The presentation of local and cultural structures of the host nations can be detected instantaneously from the opening to the closing ceremonies. In the competition of the Games, we also can see and find cultural traces of other countries from the presentation of their athletes. And, by virtue of online means of social media individuals from many different cultures can 'be there' and 'be with' athletes and audiences interacting interculturally at the global village of the Olympic Movement.

All these elements of the Olympic Games, as global media events, reflect the characteristics of globalization. As we have mentioned in the second section, Roche distinguishes two paradigms of globalization, 'basic globalisation' and 'complex globalisation'. ${ }^{62} \mathrm{He}$ argues that the Olympics should be considered in a complex context, while Olympic television, as a global 'media event', shows the perspective of 'basic globalisation' because the way that television delivers information is standardized and uniform with a deterministic process and audiences, in a traditional sense, view the ceremonies or competitions from nearly the same angle. The comments from the interpreters mainly represent the national guidance of public opinion. The examination of cultural exchange via social media of the Olympics, as we argue, should adopt the complex paradigm. The complex paradigm emphasizes the duality of individual and collective effort, national and international organizations, which implicate differentiation and particularization. Furthermore, the complex paradigm recognizes the temporal and spatial differences on sub-national and transnational levels. The complex paradigm characteristics of social media correspond to the interculturalism formula, which we have already discussed above, when we further studied the coexistence of cultural diversity and exchange in the Olympic Movement.

Social media has been growing rapidly in an unpredictable way since it first stepped on the stage of the 2008 Beijing Olympic Games. The 2012 London Olympics brought the word Socialympics' into our vision, but it is just at a starting point or an early stage for researches on the topic of this paper. Further research requires more specific data and interdisciplinary support for collecting necessary information. Faced with these changes and challenges, our research interest is and will be on the cultural exchange issue of the Olympic Games, especially in relation to the intercultural perspective and paradigms since this is a dynamic process happening in our daily life.

\section{Notes}

1. T.S. Eliot, Notes Towards the Definition of Culture (London: Faber \& Faber 2010), xv.

2. Ibid., 1.

3. Douglas Kellner, Media Culture: Cultural Studies, Identity and Politics between the Modern and the Post-Modern (London: Routledge, 1995), i. 
4. Maurice Roche, 'Olympic and Sport Mega-Events as Media-Events: Reflections on the Globalisation Paradigm', in Kevin Wamsley, Bob Barney and Scott Martyn (eds), The Global Nexus Engaged: Past, Present, Future Interdisciplinary Olympic Studies (London, ON: International Centre for Olympic Studies, University of Western Ontario, 2002), 2-3, The differences between Basic paradigm and Complex paradigm can be summarized as four perspectives, respectively. Basic paradigm: (1) globalization is a deterministic process; (2) it requires the promotion of standardization and uniformity in all spheres of life. (3) Globalization involves a historically unprecedented experience of 'one world' and of 'compression' of social space and time. (4) Globalization impacts are mainly felt at the national rather than sub- or transnational levels. Complex paradigm: (1) it also involves the possibility for collective agency and influence by political and cultural collectivizes such as nations and international organizations and movements. (2) It also involves differentiation and particularization; (3) it also involves the reconstruction of temporal and spatial distance and differences; (4) it also involves the sub-national levels and transnational levels.

5. Caleb Rosado, Toward a Definition of Multiculturalism, for Change in Human Systems, 1997, http://rosado.net/pdf/Def_of_Multiculturalism.pdf (accessed 27 June 2016), 2.

6. Yoshinobu Hakutani, Postmodernity and Cross-Culturalism (Madison: Fairleigh Dickinson University Press, 2002), 14. Hakutani comments, 'human existence can be achieved in ways that do not necessarily assert self by excluding other: truth is often a revelation from other'.

7. T. Cantle, Interculturalism: The New Era of Cohesion and Diversity (London: Palgrave Macmillan, 2012), 32.

8. Ibid., 2.

9. A. Lentin, 'Replacing "Race", Historizing the "Culture" in the Multiculturalism', Patterns of Prejudice, 39, no. 4 (2005), 379-96.

10. Nasar Meer and Tariq Modood, 'How Does Interculturalism Contrast with Multiculturalism?' Journal of Intercultural Studies 33, no. 2 (2012), 175. Original comments, '.. until interculturalism as a political discourse is able to offer a distinct perspective, one that can speak to a variety of concerns emanating from complex identities and matters of equality and diversity in a more persuasive manner than at present, interculturalism cannot, intellectually at least, eclipse multiculturalism, and so should be considered as complementary to multiculturalism?

11. Geoffrey B. Levey, 'Interculturalism vs. Multiculturalism: A Distinction Without a Difference?' Journal of Intercultural Studies 33, no. 2 (2012), 218.

12. Ibid., 223.

13. Ibid.

14. Gérard Bouchard, 'What is Interculturalism?' McGill Law Journal (2011), 437-68.

15. Ibid., 445-62.

16. Ibid., 437.

17. See, John Slater, 'Changing Partners: The Relationship Between the Mass Media and the Olympic Games', Fourth International Symposium for Olympic Research (Ontario: University of Western Ontario, 1998), 49-68; Also Maurice Roche, Mega-Events and Modernity: Olympics and Expos in the Growth of Global Culture (London: Routledge, 2000); Roche, 'Olympic and Sport Mega-Events as Media-events'; Bruce Kidd, 'The Olympic Movement and the SportsMedia Complex', Sport in Society: Cultures, Commerce, Media, Politics 16, no. 4 (2013), 439-48.

18. Slater, 'Changing Partners'.

19. Roche, Mega-Events and Modernity, and Roche, 'Olympic and Sport Mega-Events as MediaEvents'.

20. Roche, Mega-Events and Modernity, 159.

21. Slater, 'Changing Partners', 51.

22. Ibid., 51.

23. Ibid. See also John J. MacAloon, This Great Symbol: Pierre de Coubertin and the Origins of the Modern Olympic Games (Chicago: University of Chicago Press, 1981).

24. Roche, Mega-Events and Modernity, 162. Emphasis added.

25. Ibid.

26. Four time periods were proposed by Slater. 
27. Slater, 'Changing Partners', 53. Also, 'Olympics Lead in Appeal for Sports Experts: DempseySchmeling Title Bout is Next Choice', New York Times, 22 January 1932, 23.

28. Roche, Mega-Events and Modernity, 164.

29. Daniel Dayan and Elihu Katz, Media Events: The Live Broadcasting of History (Cambridge: Harvard University Press, 1994), Chapter 3, especially page 54.

30. Roche, Mega-Events and Modernity, 164.

31. Ibid., 163.

32. Slater, 'Changing Partners', 53.

33. Sut Jhally, 'The Spectacle of Accumulation: Material and Cultural Factors in the Evolution of the Sport/Media Complex', The Insurgent Sociologist 12, no. 3 (1984), 41-57, also Kidd, 'The Olympic Movement and the Sports-Media Complex', 439-48.

34. John MacAloon, ed., Rite, Drama, Festival, Spectacle (Philadelphia: The Institute of Human Issues, 1984).

35. Slater, 'Changing Partners', 54.

36. Ibid. According to Slater, ibid., 55, 'In 1960, television provided only one of every four hundred dollars of the cost of hosting the summer Olympics. In 1972, one of every fifty dollars was provided by television; in 1980, one of every fifteen dollars; by 1984, one of every three dollars of Olympic host costs were paid for from television revenues'.

37. 'Olympic Marketing Agenda Established for New Millenium', Marketing Matters: The Olympic Marketing Newsletter, no. 8 (Spring 1996), 2. Also Slater, 'Changing Partners', 60.

38. For an example, see the original statement: 'To ensure the widest possible television audience for the Olympic Games, Olympic broadcast rights are sold to broadcast networks that can guarantee the broadest free-to-air coverage throughout their respective territories' in 'Athens 2004 Olympic Broadcast Report', 78, https://stillmed.olympic.org/media/Document\%20 Library/OlympicOrg/IOC/How_We_Do_It/Broadcasters/EN_Athens_2004_Broadcast_ Report.pdf.

39. Roche, Mega-Events and Modernity, 187. Also J. Larson and H-S Park, Global Television and the Politics of the Seoul Olympics (Oxford: Westview Press, 1993).

40. 'Athens 2004 Olympic Broadcast Report', 77.

41. Jilly Traganou, Designing the Olympics: Representation, Participation, Contestation (New York: Routledge, 2016), 137.

42. Kim Bissell and Stephen Perry, The Olympics, Media and Society (New York: Routledge, 2015), 61; also Y. Tang, 'Beijing Olympic Opening Ceremony: Zhang Yimou Keeps Everyone Guessing', China Today, 3 (March 2008), 52-5.

43. For instance, the presentations on the four great inventions of ancient China and the hi-tech symbol of modern China. Luo Qing and Giuseppe Richeri, Encoding the Olympics: The Beijing Olympic Games and the Communication Impact Worldwide (London: Routledge, 2013), 189.

44. Roche, Mega-Events and Modernity, 165. See also Dayan and Katz, Media Events, 142-5.

45. Roche, Mega-Events and Modernity, 165.

46. Alpha Digital, http://alphadigital.com.au/socialympics-social-media-at-the-olympics/ (accessed 27 June 2016).

47. Source: Facebook, http://newsroom.fb.com/company-info/ (accessed 27 June 2016).

48. Alpha Digital, http://alphadigital.com.au/socialympics-social-media-at-the-olympics/ (accessed 27 June 2016).

49. Source: Twitter, https://about.twitter.com/company (accessed 27 June 2016).

50. Daniel McLaren, http://digitalsport.co/the-socialympics (accessed 27 June 2016).

51. Neil Vidyarthi, 'Social Times', http://www.adweek.com/socialtimes/the-london-2012socialympics-infographic/103811 (accessed 27 June 2016).

52. Alpha Digital, http://alphadigital.com.au/socialympics-social-media-at-the-olympics/ (accessed 27 June 2016).

53. Roche, Mega-Events and Modernity, 191. See also M. de M. Spa, N. Rivenburgh, and J. Larson, Television in the Olympics (Luton: John Libbey Media, 1995), 248.

54. Roche, Mega-Events and Modernity, 166.

55. Ibid. 
56. Ibid.

57. International Olympic Committee, 'Olympic Charter', 2015, 13.

58. Ibid., 17.

59. S.R. Veil, T. Buehner, and M.J. Palenchar, 'A Work-in-Process Literature Review: Incorporating Social Media in Risk and Crisis Communication', Journal of Contingencies and Crisis Management 19, no. 2 (2011), 110-22. See also Angle Tesorero, 'The Characteristics of Social Media?, Home of Service, 2013, http://homeofservice.com/blogs/21/the-characteristics-ofsocial-media/\#.V3E5nvkrK70 (accessed 27 June 2016).

60. W. Timothy Coombs, Ongoing Crisis Communication: Planning, Managing, and Responding, 4th ed. (California: Sage, 2014), 19.

61. Marshall McLuhan used the term 'global village' in 1962 in his book, The Gutenberg Galaxy: The Making of Typographic Man (Toronto: University of Toronto Press, 1962), 31: 'But certainly the electro-magnetic discoveries have recreated the simultaneous "field" in all human affairs so that the human family now exists under conditions of a "global village".

62. Roche, 'Olympic and Sport Mega-Events as Media-Events', 2-3.

63. 'Olympic Broadcast Reports' (2004-2012).

\section{Disclosure Statement}

No potential conflict of interest was reported by the author.

\section{Notes on Contributor}

Yinya Liu is an assistant lecturer in Chinese Studies at the National University of Ireland Maynooth. Her main research interests are Chinese Philosophy, Chinese Literature, Cultural Studies, and Philosophy in Literature.

\section{ORCID}

Yinya Liu (D) http://orcid.org/0000-0002-9406-4384 